\title{
COOPETIÇÃo COMO ESTRATÉGIA DE AUXÍLIO NA GESTÃo DE RISCOS EM CADEIAS DE SUPRIMENTOS
}

\section{RESUMO}

Conforme as pesquisas e a adoção da gestão da cadeia de suprimentos avançam, novos desafios são impostos para pesquisadores e gestores da área. Nesse sentido, a gestão de risco em cadeia de suprimentos (Supply Chain Risk Management - SCRM) tem se mostrado um campo proeminente por sugerir estratégias e planos de ação para mitigar os riscos da operação conjunta. Concomitante a isso, observa-se que o conceito de Coopetição advoga que duas organizações competidoras podem trabalhar juntas em algumas atividades na forma de uma aliança estratégica, colaborando para que ambas atinjam a máxima eficiência. O intuito desse trabalho é, portanto, propor a extensão desse conceito para as atividades de SCRM, tratando a Coopetição como uma ação que pode ser adicionada aos esforços de gestão de riscos a fim de tornar as cadeias de suprimentos mais resilientes. Para tanto, através de uma pesquisa bibliográfica e exploratória que utiliza dados secundários, foram elaboradas duas proposições que versam sobre a possibilidade da adição de um coopetidor para a redução de riscos em cadeias de suprimentos e sobre a viabilidade da Coopetição equilibrada alterar o perfil de uma cadeia para um modelo resiliente. Embora as proposições apresentadas necessitem ainda de verificação empírica, considera-se que esse é um bom início para as discussões quanto aos benefícios e vantagens competitivas que a adoção da Coopetição em atividades de SCRM pode trazer às organizações.

Palavras-chave: Gestão de Riscos; Gestão de Riscos na Cadeia de Suprimentos; Coopetição.

\section{COOPETITION AS SUPPORT STRATEGY FOR SUPPLY CHAIN RISK MANAGEMENT}

\begin{abstract}
As supply chain management research and its adoption advance, new challenges are imposed for researchers and managers. Accordingly, the supply chain risk management (SCRM) has been a prominent field because it suggests strategies and action plans to mitigate these risks. On the other hand, it is observed that the coopetition concept advocates that two competing organizations can work together in some activities in the form of a strategic alliance, contributing to achieve maximum efficiency. Therefore, the purpose of this paper is to propose the extension of this concept into the activities of SCRM, treating coopetition as an action that can be added to the risk management efforts in order to make supply chains more resilient. Thus, through an exploratory literature search that uses secondary data, we drawn two propositions that deal with the possibility of adding a coopetitor to reduce risks in supply chains and on the feasibility of balanced coopetition changes the profile of a supply chain to a resilient model. Although these propositions require further empirical verification, it is believed that this is a good start for discussions about the benefits and competitive advantages that the adoption of coopetition in risk management activities in supply chains can bring to organizations.
\end{abstract}

Keywords: Risk Management; Supply Chain Risk Management; Coopetition. 
COOPETITION COMO ESTRATEGIA PARA LA AYUDA EN GESTIÓN DE RIESGOS EN CADENAS DE SUMINISTRO

\section{RESUMEN}

A medida que la investigación y la adopción de los avances de gestión de la cadena de suministro, los nuevos retos que se imponen a los investigadores y empresarios de la zona. En este sentido, la gestión del riesgo en la cadena de suministro ( Supply Chain Gestión de Riesgos - SCRM ) ha sido un campo importante para sugerir estrategias y planes de acción para mitigar los riesgos de la operación conjunta. Concomitante a esto, se observa que el concepto de cooperación competitiva aboga por que dos organizaciones competidoras pueden colaborar en algunas actividades en la forma de una alianza estratégica, que contribuye tanto a lograr la máxima eficiencia . Por ello, el propósito de este trabajo es proponer la extensión de este concepto a las actividades de SCRM , tratar coopetición como una acción que se puede agregar a los esfuerzos de la gestión de riesgos con el fin de hacer que las cadenas de suministro más resistentes. Para ello, a través de una literatura y la investigación exploratoria utilizando datos secundarios, dos proposiciones que tienen que ver con la posibilidad de añadir una coopetidor para reducir los riesgos en las cadenas de suministro y sobre la viabilidad de la cooperación competitiva equilibrada estaban dispuestos a cambiar el perfil de un cadena a un modelo elástico. Aunque las proposiciones siguen requiriendo la verificación empírica, se considera que este es un buen punto de partida para los debates sobre los beneficios y las ventajas competitivas que la adopción de cooperación competitiva en actividades SCRM puede aportar a las organizaciones.

Palabras-clave: Gestión de Riesgos; Gestión de Riesgos; Cadena de Suministro; Coopetición.

João Batista de Camargo Junior ${ }^{1}$ Valdir Antonio Vitorino Filho ${ }^{2}$ Silvio Roberto Ignacio Pires ${ }^{3}$ Mário Sacomano Neto ${ }^{4}$

\footnotetext{
${ }^{1}$ Mestre em Administração pela Universidade Metodista de Piracicaba - UNIMEP. Professor da Universidade Metodista de Piracicaba - UNIMEP. Brasil. E-mail: jocamarg@ unimep.br

${ }^{2}$ Mestre em Administração pela Universidade Metodista de Piracicaba - UNIMEP. Coordenador do Curso de Administração da Faculdade Cenecista de Capivari. Brasil. E-mail: valdir.vitorino@gmail.com

${ }^{3}$ Doutor em Engenharia de Produção pela Universidade de São Paulo - USP. Professor da Universidade Metodista de Piracicaba - UNIMEP. Brasil. E-mail: sripires@ unimep.br

${ }^{4}$ Doutor em Engenharia de Produção pela Universidade Federal de São Carlos - UFSCAR. Professor da Universidade Federal de São Carlos - UFSCAR. Brasil. E-mail: msacomano@ufscar.br
} 


\section{INTRODUÇÃO}

Devido às diversas mudanças que as organizações enfrentam atualmente, especialmente por conta do crescimento da integração dos mercados e do aumento da exigência dos consumidores, a gestão da cadeia de suprimentos (Supply Chain Management SCM) tem demonstrado ser capaz de gerar vantagens competitivas importantes. Nesse sentido, a integração de processos e a cooperação/colaboração entre empresas da cadeia de suprimentos se tornaram elementos básicos de uma efetiva SCM (Pires, 2009). Porém, quando as empresas trabalham de forma colaborativa em uma cadeia de suprimentos, invariavelmente se expõe aos diversos riscos que a operação conjunta traz consigo. Assim, uma metodologia de gestão de riscos pode ser aplicada a essas relações no intuito de diminuir a probabilidade de ocorrência desse risco, assim como o impacto que ele possa a vir a causar.

Do desenvolvimento dos estudos da aplicação da gestão de riscos em cadeias de suprimentos, surgiu o conceito de gestão de riscos em cadeia de suprimentos (Supply Chain Risk Management - SCRM), cujo foco é compreender e, de forma mais abrangente, criar mecanismos para evitar os efeitos que os riscos podem ocasionar em uma cadeia de suprimentos (Norrman \& Jansson, 2004). Desse modo, a SCRM se torna um desdobramento das práticas e iniciativas da gestão da cadeia de suprimentos, tendo como objetivo identificar os fatores potenciais de riscos e prescrever ações e planos adequados para mitigá-los (Singhal, Agarwal, \& Mittal, 2011). Concomitante a essa observação, nota-se que a adoção das estratégias de Coopetição (cooperação e competição simultâneas) tem se tornado cada vez mais frequente em determinados setores industriais e alguns autores elencam dois principais motivos para esse comportamento: (a) a experiência fornece às empresas uma vantagem competitiva que afeta positivamente a probabilidade de sucesso das atividades nessas empresas; e (b) a experiência de Coopetição fornece às empresas uma posição privilegiada dentre de uma rede de interorganizações, devido ao aumento na quantidade de ligações, conhecimento e informações que as empresas alcançam (Bengtsson \& Kock, 2000; Dagnino \& Padula, 2002; Garraffo, 2002; Nalebuff \& Brandenburger, 1996; Schiavone \& Simoni, 2011; Zhang \& Frazier, 2011).

Devido a esses e outros benefícios que a adoção da estratégia de Coopetição pode trazer às organizações envolvidas torna-se possível teorizar que, ao adotar a Coopetição em cadeias de suprimentos, as empresas poderiam melhorar a qualidade e efetividade de sua gestão, traduzindo-se em benefícios ao cliente final. Além disso, a estratégia aplicada aos esforços de SCRM tem o potencial de alavancar essas práticas, uma vez que a utilização da cooperação com competidores pode diminuir o risco das operações e, consequentemente, de toda a gestão da cadeia de suprimentos. Nesse ponto faz-se importante observar que a estratégia de Coopetição pode ser benéfica à gestão de risco em cadeias de suprimentos quando tratada como atividade complementar, ou seja, outras estratégias de SCRM debatidas na literatura continuam sendo importantes para mitigação dos riscos nas cadeias de suprimentos. Desse modo, este artigo tem como objetivo debater a possibilidade da adoção da estratégia de Coopetição (competição e cooperação simultâneas) nas atividades de SCRM, com o intuito de minimizar e combater os efeitos dos riscos inerentes à SCM.

Para tanto, essa pesquisa debate e fornece exemplos de como a Coopetição pode auxiliar na diminuição dos riscos, de acordo com a categorização elaborada por Miccuci (2008) para os riscos em cadeias de suprimentos. Dessa discussão resultam duas proposições de pesquisa: (1) Um coopetidor pode aumentar a capacidade de antecipação a possíveis problemas que comprometam as operações em uma cadeia de suprimentos; (2) Uma maior resiliência da cadeia de suprimentos será alcançada quando existir uma situação de Coopetição equilibrada (cooperação e competição sendo igualmente distribuídas). Esse estudo caracteriza-se como uma pesquisa bibliográfica e exploratória, com a utilização de dados secundários. Segundo Collins e Hussey (2005) a pesquisa bibliográfica envolve a leitura, análise e interpretação de livros e periódicos. Para Roesch (1999) a pesquisa exploratória busca avaliar a aplicação de conceitos existentes a problemas ou a novas teorias que podem ser desenvolvidos. Já dados secundários são informações já existentes que são empregadas e analisadas, com o intuito de complementar as novas investigações (Collins \& Hussey, 2005).

O trabalho está estruturado como segue: na seção 2, são apresentadas as definições e contextualizações sobre risco e gestão de riscos; na seção 3 é apresentada a questão da gestão de riscos na cadeia de suprimentos; na seção 4 encontram-se as definições e principais modelos em Coopetição; na seção 5, são realizadas as discussões que permeiam a pesquisa acerca da contribuição da Coopetição para a gestão de riscos na cadeia de suprimentos, bem como as proposições de pesquisa; na seção 6 são tecidas algumas considerações finais do estudo, e por fim têmse as referências bibliográficas utilizadas ao longo da pesquisa. 


\section{GESTÃO DE RISCOS}

A preocupação com os riscos inerentes a uma organização e, consequentemente, com a melhor forma de gerenciá-los, tem demonstrado ser um cuidado crescente dos administradores. Isso porque, devido ao aumento da interdependência dos mercados ocasionado pelo desenvolvimento da globalização aliado a velocidade com que movimentações competitivas propagam-se, as empresas têm sido obrigadas a gerar e manter estratégias competitivas para sustentar seu negócio (Kimura \& Perera, 2005). No contexto competitivo atual, a compreensão desse conceito e de seus desdobramentos torna-se ainda mais útil para que as empresas aperfeiçoem sua capacidade de antecipação aos possíveis problemas que possam afetar suas operações.

Porém, a fim de melhor compreender o significado da gestão de riscos, faz-se necessário debater inicialmente o conceito de risco. O risco é o produto de dois fatores inter-relacionados. O primeiro deles é a incerteza, que se refere à imprevisibilidade do ambiente ou das variações organizacionais que afetam a performance corporativa ou, ainda, a inadequabilidade de informação sobre essas variáveis. O segundo fator que compõe um risco é o impacto, que é medido pelos potenciais custos ou perdas não previstas advindos da interrupção de um determinado evento (Zsidisin, Ragatz, \& Melnyk, 2005). Por sua vez, Banks (2005) conceitua o risco como uma chance de perda combinada com o grau de probabilidade dessa perda, demonstrando seu foco principalmente em riscos de acidentes e riscos financeiros inerentes às organizações. Essa definição de risco, devido a sua abordagem relacionada a aspectos específicos, não traz consigo um fato importante sobre o conceito, que é a compreensão de que um risco também pode ter um impacto benéfico à empresa. Assim, percebe-se que o conceito de risco pode ter diversas definições que dependem de sua aplicação específica e do contexto situacional.

O simples fato de existir atividade em uma organização abre a possibilidade de ocorrência de eventos ou situações cujas consequências constituem oportunidades para obter vantagens ou, então, ameaças ao sucesso. Desse modo, a definição de risco como a combinação da probabilidade de um acontecimento, ou sua incerteza, e de suas consequências para o negócio, ou seu impacto, acaba por traduzir melhor o conceito e levar as organizações a uma melhor compreensão de como agir para evitá-los ou aceitá-los, dependendo de seu resultado (Federation of European Risk Management Associations [FERMA], 2003). Nesse contexto, a gestão de riscos traduz-se em uma metodologia proativa de análise dos riscos, que é colocada em prática ao compreenderem-se as atividades realizadas no passado, no presente e, majoritariamente, no futuro, no intuito de lidar com a incerteza. Essa abordagem pode traduzir-se na postura de esperar o inesperado, analisando processos organizacionais não pelos níveis de conformidade que atingem, mas sim pensando em possíveis falhas que possam ocasionar e nos impactos da interrupção desses serviços na organização (Guimarães \& Carvalho, 2012). Já Miccuci (2008) menciona que a gestão de risco é a capacidade de lidar com os riscos e suas consequências e fazer com que os objetivos organizacionais sejam atingidos graças a ações que devem ser tomadas antes e depois da ocorrência de um sinistro, dividindo-se em ações preventivas ou ações que minimizem o impacto do fato acontecido.

Quanto às ações preventivas ou reativas tomadas pelas empresas, elas são classificadas em relação à perda que o risco pode proporcionar. Desse modo classificam-se em ações de redução (loss reduction), ou seja, ações que reduzam ou removam a perda que venha a ocorrer ou ações de transferência (loss transfer), que são aquelas que transferem para um terceiro o custo de recuperação ou parte dele. As organizações podem ainda tomar ações de retenção (loss retention), que são as que devem ser tomadas caso a perda não consiga nem ser reduzida nem transferida para um terceiro (Mehr \& Hedges, 1974). Desse modo, pode-se considerar que a gestão de riscos é o processo de análise e tomada de decisões a respeito dos riscos e sua subsequente implementação. A partir do conhecimento pleno do risco e de seu potencial impacto na organização, ações são tomadas para mitigar a probabilidade de sua ocorrência. Por fim, deve-se constantemente acompanhar os riscos identificados, em um processo de monitoramento constante e pró-ativo (Miccuci, 2008). Em uma abordagem mais completa, a norma de gestão de riscos elaborada pela Federation of European Risk Management Associations propõem que as seguintes etapas sejam respeitadas para uma eficiente gestão de riscos (Ferma, 2003):

- Avaliação, levando em conta os objetivos da organização, e composta pela análise, identificação, descrição e estimativa dos riscos;

- Comparação dos riscos, que é o processo de comparar os riscos estimados com os critérios de riscos definidos pela organização;

- Tratamento dos riscos, ou o processo de selecionar e implementar medidas para modificar um risco;

- Comunicação do risco, incluindo a comunicação interna e externa dos riscos e de seus potenciais impactos para os stakeholders;

- Monitoramento e revisão do processo de gestão de riscos, no intuito de garantir que os riscos estão sendo acompanhados e que o processo de gestão de riscos continua a atender os objetivos da organização.

Paralela à gestão de risco está a questão de como mitigar as consequências de um acidente se ele 
vier a acontecer, ou seja, como lidar com a situação de uma maneira que minimize o impacto no negócio. Essa ação pode ser conduzida por um processo denominado gestão de continuidade de negócios (Business Continuity Management - BCM) que relaciona-se com as atividades de gestão que buscam fornecer os meios para que as operações de funções essenciais da organização permaneçam contínuas em quaisquer circunstâncias. Em muitos aspectos, a gestão de riscos e o BCM são sobrepostos, e pode-se argumentar que o plano de continuidade de negócios é a ação da gestão de risco a ser tomada para os riscos de baixa probabilidade, mas cujo potencial impacto pode vir a se traduzir em fracasso comercial (Norrman \& Jansson, 2004). Desse modo, a gestão de riscos deve ser um processo contínuo e em constante desenvolvimento dentro da organização. A empresa deve, portanto, analisar metodicamente todos os riscos inerentes às atividades realizadas e procurar integrar a gestão de riscos em sua cultura. Por conseguinte, essa política deve traduzir a estratégia organizacional em objetivos táticos e operacionais, procurando atribuir responsabilidades na gestão dos riscos para todas as funções da organização como parte integrante da respectiva descrição de função (Ferma, 2003).

Como se vê, a gestão de riscos foca nos desafios internos da organização, ou seja, volta-se para a análise, priorização, tomada de ação e monitoramento dos riscos inerentes a uma dada empresa. Porém, quando se pensa em cadeias de suprimentos, observase que os riscos se dividem entre todos os participantes da cadeia, e que administrar riscos de forma isolada para cada elo pode não ser suficiente para a operação conjunta. Desse modo, faz-se necessário um planejamento conjunto de riscos ao longo da cadeia de suprimentos.

\section{GESTÃO DE RISCOS EM CADEIAS DE SUPRIMENTOS}

A partir da década de 1990, o conceito de gestão da cadeia de suprimentos (SCM) ganhou relevância no meio empresarial e acadêmico, uma vez que as empresas começaram a perceber as vantagens de uma operação que integrasse todos os parceiros de uma cadeia e permitisse um fluxo contínuo e racional de informações e produtos visando o melhor atendimento ao consumidor final (Pires, 2009). Desde então, observa-se que diversas organizações têm implementado iniciativas e práticas de SCM e conseguindo gerar vantagens competitivas importantes em seus negócios. Porém, quanto mais uma cadeia de suprimentos se torna enxuta e integrada, percebe-se que são maiores as probabilidades que incertezas, acidentes e o próprio desempenho de um elo afetem os demais participantes da cadeia. Esse acréscimo dos riscos percebidos tem ocorrido especialmente por conta da globalização das cadeias, da redução da base de fornecedores, de processos mais integrados entre os elos, do aumento da demanda por entregas mais rápidas e por um ramp-up mais rápido da demanda no início do ciclo de vida de produtos (Norrman \& Jansson, 2004).

Desse modo, no intuito de enfrentar esses desafios, as organizações tendem a não mais concentrar-se apenas em suas próprias incertezas, mas sim compreender e aplicar os conceitos de gestão de riscos em toda a extensão da cadeia de suprimentos. A necessidade é, portanto, de um foco mais holístico para os riscos envolvidos no negócio, compreendendo como situações únicas podem ocasionar problemas para os diversos atores que compartilham os benefícios, mas, também, os riscos de uma operação conjunta. Por esse motivo, Norrman e Jansson (2004) afirmam que o foco da SCRM é compreender, e mais especificamente, tentar evitar os efeitos em cascata que os desastres, ou mesmo perturbações de negócios menores, podem ocasionar em uma cadeia de suprimentos. Corroborando essa visão, Singhal et al. (2011) afirmam que a SCRM emergiu como uma extensão natural da gestão da cadeia de suprimentos com o objetivo principal de identificar as fontes potenciais de riscos, sugerindo medidas e planos adequados para mitigá-los. Porém, os autores ressaltam que o desenvolvimento de um programa efetivo de SCRM é sempre uma tarefa crítica, que requer habilidades e competências da organização em várias áreas. A implementação do conceito exige, portanto, conhecimento das funções de negócios, tendências de mercado, situação financeira e de infra-estrutura de todos os elos envolvidos na cadeia de suprimentos.

Desse modo, os riscos envolvidos em uma operação conjunta são mais complexos que os observados em uma unidade operacional isolada e requerem um conhecimento mais abrangente dos processos envolvidos. Voltando-se para essa questão Donato, Rossi e Bezerra (2007) classificam os riscos em cadeias de suprimentos em riscos financeiros, riscos de caos, riscos de decisão e riscos de mercado. Já Miccuci (2008), em uma abordagem mais direta, notou que as fontes de riscos em cadeias de suprimentos situam-se em três níveis denominados risco ambiental, que surgem independentemente da existência da cadeia, riscos inerentes à cadeia, que surgem por causa de sua existência e riscos organizacionais, que são aqueles internos aos membros da cadeia. Tal autora ainda categoriza os riscos mais comuns de acordo com o Quadro 1, no intuito de tornar clara as dimensões reais de ocorrência de um risco e servir como base para o processo de avaliação de riscos. 
Coopetição como Estratégia de Auxílio na Gestão de Riscos em Cadeias de Suprimentos

\begin{tabular}{|c|c|c|}
\hline CATEGORIZAÇÃO & NÍVEL & EXEMPLOS \\
\hline Risco de Inércia & Organizacional & Falta de competitividade e Riscos relacionados a competências \\
\hline Risco de Capacidade & Organizacional & Restrição de capacidade produtiva e fornecimento \\
\hline Risco Financeiro & Organizacional & Calote, gerenciamento de custos e precificação \\
\hline Risco de Suprimentos & Inerente à cadeia & Número de fornecedores disponíveis e sua saúde financeira \\
\hline Riscos Estratégicos & Inerente à cadeia & Ativos específicos / investimentos necessários \\
\hline Risco nos Relacionamentos & Inerente à cadeia & Dependência do relacionamento e perda de visibilidade e controle \\
\hline Risco Regulatório / Legal & Ambiental & Responsabilidades legais, risco fiscal e performance ambiental \\
\hline Risco de Demanda & $\begin{array}{l}\text { Organizacional } \\
\text { Inerente à Cadeia }\end{array}$ & Capacidade de acompanhar as flutuações de demanda \\
\hline $\begin{array}{c}\text { Risco na Infraestrutura de } \\
\text { Apoio } \\
\end{array}$ & $\begin{array}{c}\text { Organizacional } \\
\text { Inerente à Cadeia }\end{array}$ & Risco na infraestrutura de comunicação nacional / internacional \\
\hline Risco ao Cliente & $\begin{array}{c}\text { Organizacional } \\
\text { Inerente à Cadeia }\end{array}$ & Risco na expectativa do cliente e risco de reputação \\
\hline Risco de Interrupções & $\begin{array}{c}\text { Organizacional } \\
\text { Inerente à Cadeia } \\
\text { Ambiental }\end{array}$ & Desastres naturais, Fator humano, Atrasos, Qualidade \\
\hline
\end{tabular}

Quadro 1 - Níveis e exemplos de riscos em cadeias de suprimentos de acordo com sua categorização

Fonte: Miccuci, V.C.G.S. (2008). Um modelo pró-ativo de gestão de riscos na cadeia de suprimentos. Tese de doutorado, Pontifícia Universidade Católica do Rio de Janeiro, Rio de Janeiro, RJ, Brasil. Disponível:

http://www.maxwell.lambda.ele.puc-rio.br/Busca_etds.php?strSecao=resultado\&nrSeq=13213@2.

Tendo-se compreendido os riscos a que as cadeias de suprimentos estão sujeitas, Sheffi (2005) indica que as organizações precisam compreender o conceito de resiliência e estabelecer processos proativos de identificação das fontes desses riscos, mensurando os impactos que podem vir a ocorrer na cadeia e definindo medidas de contenção para prevenir ou minimizar os impactos. Nesse contexto, a resiliência é um termo usado ara definir a propriedade da cadeia de retornar à sua forma original após ter sido submetida a desafios relacionados às mudanças e incertezas. Sheffi (2005) ainda notou que diversas empresas não possuem um processo formal de estimativa dos riscos, se limitando tão somente a listar os possíveis problemas que estão sujeitas. Desse modo, o autor destaca duas atividades importantes para uma organização trabalhar com foco em sua resiliência. A primeira é a construção de redundância, que significa a utilização de mais do que um fornecedor para atender as necessidades da organização. A segunda atividade é a flexibilidade das cadeias de suprimentos, ou sua capacidade de alterar suas características rapidamente quando necessário.

A partir dessas atividades, torna-se possível identificar quatro princípios para melhorar a resiliência de uma cadeia de suprimentos e assim diminuir a probabilidade de riscos ocorrerem. O primeiro refere-se ao reprojeto da cadeia onde, ao invés da construção de um processo integrado que vise somente otimizar o custo e o serviço ao cliente, as organizações envolvidas projetem seus processos observando os pontos de estrangulamento dos fluxos de negócio. $\mathrm{O}$ segundo princípio volta-se para o fator colaborativo, que preconiza que os atores devem desenvolver e manter relações de colaboração efetiva, entendendo que somente com o sucesso de todos os elos a cadeia pode atingir seus objetivos. O terceiro refere-se à agilidade da cadeia, ou a habilidade dos participantes de responder rapidamente às mudanças na demanda ou no suprimento. Por fim, o quarto princípio sugere a criação de uma cultura de gestão de risco na cadeia de suprimentos, fazendo com que os colaboradores de todas as empresas envolvidas compreendam a importância da SCRM e as vantagens de sua aplicação (Christopher \& Peck, 2004).

Quando as organizações envolvidas em uma determinada cadeia de suprimentos aplicam os princípios de resiliência, a gestão do risco se torna mais fácil, porém não menos complexa. Nesse sentido, Miccuci (2008) lembra que as técnicas e princípios de SCRM se baseiam na gestão de risco tradicional, fazendo com que suas etapas básicas adotem a mesma linha de raciocínio. Assim, o primeiro passo é a identificação dos riscos da cadeia, mapeando as operações a montante e à jusante, coletando informações sobre cada risco identificado e priorizando-se esses riscos. Em seguida, devem-se desenvolver ações preventivas de acordo com a priorização dos riscos, assim como os custos e eficácia de cada ação na situação de risco. Após a prevenção, as organizações devem estabelecer o monitoramento contínuo dos riscos por todos os elos da cadeia. Um risco menor para um dos membros da cadeia pode afetar toda a operação ou a capacidade operacional de 
outras empresas envolvidas. A identificação e a avaliação de objetivos comuns formam a base para uma estratégia de gestão de riscos que deve ser utilizada por todos os participantes do processo, desenvolvendo-se, assim, princípios para auditar, reduzir e compartilhar os riscos. É certo que os estudos acadêmicos voltados à SCRM estão ainda em estado nascente, e uma melhoria conceitual e teórica ainda faz-se necessária para desenvolver o nível de compreensão de riscos que as cadeias enfrentam, assim como as ações necessárias para mitigá-los.

\section{COOPETIÇÃO}

A Coopetição (cooperação e competição simultâneas entre as empresas) é um fenômeno que vem sendo estudado desde quando Nalebuff e Brandenburger (1996) utilizaram o termo pela primeira vez no livro intitulado "Coopetition". O conceito se apresenta como uma alternativa estratégica para as empresas alcançarem novos mercados, criarem sinergias competitivas entre os seus participantes, alcançarem novos recursos e capacidades, buscarem redução de custos com compras coletivas, desenvolverem planejamento conjuntos em novas tecnologias, produtos e processos, otimizarem atividades de distribuição, dentre outras possibilidades. De acordo com Bengtsson e Kock (2000) Coopetição "é a relação diádica e paradoxal que emerge quando duas empresas cooperam em alguma atividade, como em uma aliança estratégica, e ao mesmo tempo competem uns com os outros em outras atividades". Schiavone e Simoni (2011), por sua vez, defendem que Coopetição é o fenômeno pelo qual as empresas em um mesmo setor completam umas as outras na criação de mercado, mas competem na divisão desses mercados. Nesse sentido, Bagshaw e Bagshaw (2001) advogam que na Coopetição os concorrentes trabalham juntos para criar algo que não teriam a capacidade de realizarem sozinhos.
Zineldin (2004) lembra que as organizações do futuro devem não apenas competir com seus concorrentes convencionais, mas também considerar os benefícios potenciais da cooperação. $\mathrm{O}$ autor defende que um ambiente de negócios é altamente mutável e que novos tipos de relações (comerciais, pessoais, financeiras) acabam surgindo como uma resposta mais eficaz as mudanças nas ameaças e oportunidade ambientais. Assim, a adoção da estratégia de Coopetição pode proporcionar a sinergia necessária para planejamento, controle e gerenciamento para o alcance dos resultados esperados pelas organizações. Yadong (2007) destaca ainda que algumas áreas funcionais são mais propensas a cenários de Coopetição como, por exemplo, terceirização, acordos de fornecimentos, co-produção, atividades da cadeia de valores: como P\&D (Planejamento e Desenvolvimento), sistemas de informação, e ainda, conhecimentos de gestão. Já Zhang e Frazier (2011) entendem que as relações de concorrência têm sido consideradas como as políticas de preços adotadas pelas empresas, mas propõem que mesmo em setores econômicos muito competitivos a relação de Coopetição pode existir como uma forma de relação interfirmas.

A seguir apresentam-se, de forma sintética, quatro modelos teóricos de maior impacto para análise de Coopetição: (1) a rede de valores (Nalebuff \& Brandenburger, 1996); (2) diferentes tipos de relações de Coopetição entre concorrentes (Bengtsson \& Kock, 2000); (3) o framework da tipologia da Coopetição (Garraffo, 2002); (4) o nível da cadeia de valor e o número de firmas (Dagnino \& Padula, 2002). Para Nalebuff e Brandenburger (1996), uma rede de valores é composta por duas dimensões: a vertical e a horizontal. $\mathrm{Na}$ dimensão vertical destacam-se os clientes e os fornecedores e na dimensão horizontal encontram-se os concorrentes e os complementadores, conforme demonstrado na Figura 1.

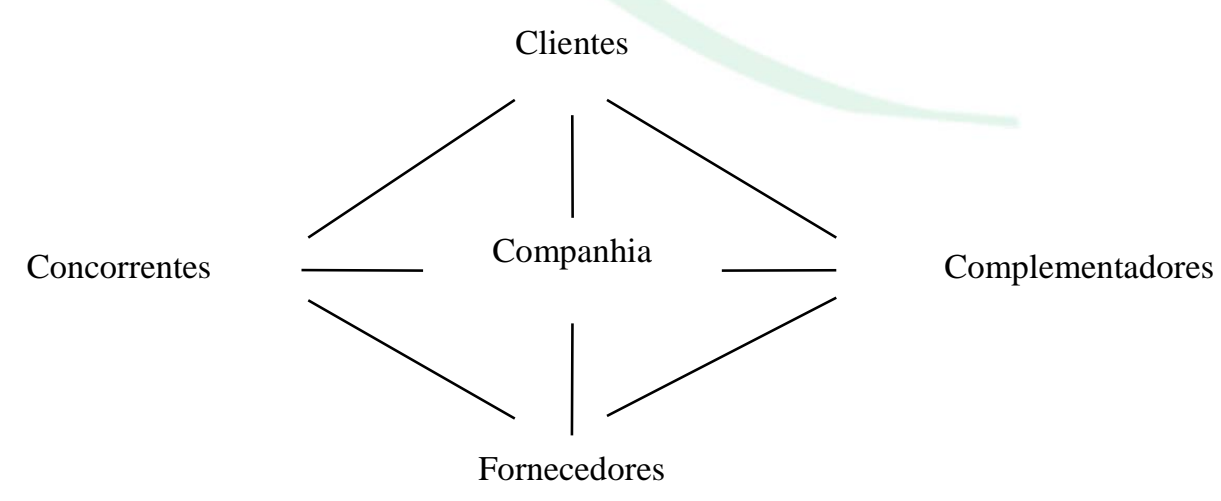

Figura 1 - Rede de Valores

Fonte: Nalebuff, B. J., \& Brandenburger, A. M. (1996). Co-opetição. Rio de Janeiro: Rocco. 
Segundo Nalebuff e Brandenburger (1996), um complementador pode ser uma pessoa, instituição, ou qualquer jogador outro ator que faça com que os clientes valorizem mais o produto quando eles o obtêm do complementador ao invés de diretamente da companhia. Já os concorrentes fazem com que os clientes valorizem menos o produto de uma companhia quando os fregueses obtêm o produto do concorrente. A rede de valores, assim, leva as organizações a formularem suas estratégias de forma a levar em consideração os tipos de relacionamentos que esperam ter com seus clientes, fornecedores, complementadores e concorrentes.

Quanto ao segundo modelo teórico de Coopetição, Bengtsson e Kock (2000) advogam que relacionamentos coopetitivos são complexos pois fazem com que as organizações tenham que lidar com duas estratégias de interação distintas: uma que favorece os interesses individuais e conflitantes, e outra que favorece os interesses comuns e as relações interpessoais. Porém, a vantagem da cooperação e competição entre empresas é a possibilidade da criação de progresso entre as organizações envolvidas, através de um relacionamento de longo prazo. Assim, as autoras demonstram que os tipos de relacionamentos entre coopetidores podem ser descritos como relacionamento dominante em cooperação, relacionamento equilibrado e relacionamento dominante em competição. Um relacionamento dominante em cooperação é aquele em que a Coopetição consiste em mais cooperação do que competição, enquanto que um relacionamento equilibrado se configura por conter cooperação e competição de formas igualmente distribuídas. Por fim, o relacionamento dominante em competição é aquele em que a Coopetição consiste em mais competição do que cooperação. Portanto, observa-se que as empresas estão mais propensas a cooperar com seus concorrentes de forma equilibrada em atividades na cadeia de suprimentos que estejam o mais distantes do cliente final possível, e podem manter um relacionamento dominante em competição em atividades mais próximas dos clientes finais (Bengtsson \& Kock, 2000).

Partindo para a análise do framework da tipologia da Coopetição elaborado por Garraffo (2002), é possível observar diferentes níveis de compromisso na criação de mercados com relação aos níveis de compromisso sobre a evolução tecnológica. Conforme demonstrado na Figura 2, esses níveis esses níveis se dividem em altos ou baixos. Para um baixo compromisso na criação de mercados e baixo compromisso na evolução tecnológica existe uma troca de conhecimento entre as empresas. Se o nível de compromisso na criação de mercados for alto e o nível de compromisso em evolução tecnológica for baixo, têm-se uma fixação de padrões. Já para altos níveis tanto na criação de mercados e evolução tecnológica um comportamento de integração dos negócios. Por fim, um baixo nível de compromisso na criação de mercados e alto nível de compromisso na evolução tecnológica proporcionam uma cooperação em P\&D.

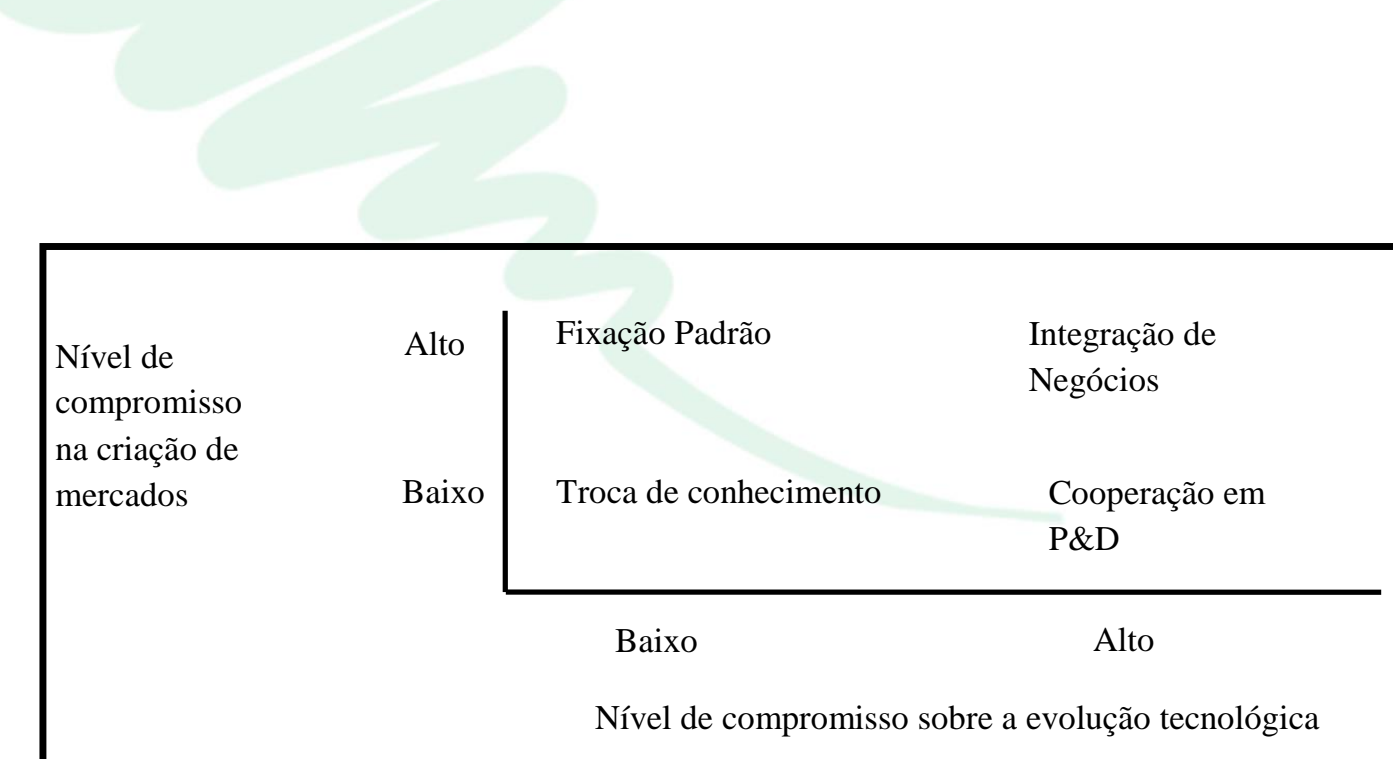

Figura 2 - Níveis de compromisso na criação de mercados com relação aos níveis de compromisso sobre a evolução tecnológica

Fonte: Garraffo, F. (2002, May). Types of coopetition to manage emerging technologies. Proceedings of the Innovative Research Management Conference, Stockholm, Sweden, 2. 
Por fim, o quarto modelo teórico para análise de Coopetição é descrito por Dagnino e Padula (2002) que averiguaram a relação entre os níveis da cadeia de valor e o número de firmas evolvidas. Os autores defendem a existência de quatro condições de Coopetição, conforme demonstrado na Figura 3: diádica única, diádica complexa, única rede $\mathrm{e}$ complexas redes. A análise dessa construção teórica propicia duas principais conclusões: (a) a interdependência das empresas é fonte de criação de valor econômico e lugar para a partilha de valor econômico; e (b) a interdependência das empresas é baseada em um jogo variável de soma positiva que pode trazer benefícios mútuos, mas não necessariamente equivalentes para os parceiros por conta de várias pressões competitivas de natureza diferente que podem comprometer sua estrutura coopetitiva (Dagnino \& Padula, 2002).

\begin{tabular}{|l|c|c|}
\hline $\begin{array}{c}\text { Nível da cadeia de valor / } \\
\text { Número de firma }\end{array}$ & Duas & Mais que duas \\
\hline Único & Coopetição diádica única & $\begin{array}{c}\text { Coopetição em } \\
\text { única rede }\end{array}$ \\
\hline Vários & $\begin{array}{c}\text { Coopetição diádica } \\
\text { complexa }\end{array}$ & $\begin{array}{c}\text { Coopetição em } \\
\text { complexas redes }\end{array}$ \\
\hline
\end{tabular}

Figura 3 - O modelo dos níveis da cadeia de valor e o número de firmas

Fonte: Dagnino, G. B., \& Padula, G. (2002, May). Coopetition strategy: a new kind of interfirm dynamics for value creation. Proceedings of the Innovative Research Management Conference, Stockholm, Sweden, 2.

Ao compreender esses principais modelos teóricos de Coopetição, Zhang e Frazier (2011) concluem que as empresas devem considerar dois tipos de efeitos na adoção de uma estratégia de Coopetição: o efeito da eficiência e o efeito cooperativo. Destacam também que os fatores que podem dificultar a formação ou continuação de uma aliança entre as empresas concorrentes são: (a) não há diferença de eficiência suficiente entre as duas empresas envolvidas na aliança e (b) custos altos de negociação, contratação e acompanhamento da aliança. Portanto, a aplicação da estratégia de Coopetição envolve sempre a formalização de um acordo contratual para que se possa atender os objetivos estratégicos das companhias envolvidas bem como ampliar a participação de mercado, melhorar a eficiência operacional e, até mesmo, proporcionar a entrada em um novo canal de distribuição.

\section{ASPECTOS DA COOPETIÇÃO COMO ESTRATÉGIA}

A estratégia empresarial pode ser definida, entre outros aspectos, como a capacidade de utilização dos recursos disponíveis para consecução dos objetivos do negócio em um dado ambiente (Vale, 2009). Nesse sentido, a teoria da dependência de recursos defende que as empresas procuram evitar a exposição de vulnerabilidades de seus recursos em relação a seus competidores no intuito de não sofrerem com os efeitos negativos que essas fraquezas podem causar no seu desempenho (Silva, 2011). Prahalad e Hamel (2005) mencionam que, na definição da estratégia de uma organização, é necessário levar em conta o fato de que seu desempenho é influenciado fortemente pela combinação de competências e de recursos que essa companhia dispõe. Desse modo, as competências essenciais são recursos de difícil imitação e que são capazes de oferecer mais valor ao cliente final e uma vantagem competitiva em relação à concorrência. Embora esses estudos exemplifiquem a importância estratégica dos recursos para as organizações, é certo que, em determinados momentos, torna-se interessante compartilhá-los com organizações concorrentes.

Isso porque, embora o comportamento competitivo possa ser visualizado como a maximização dos ganhos individuais de cada empresa, ao agir de maneira puramente competitiva é possível que os resultados obtidos sejam apenas temporários e que seja difícil manter a competitividade estratégica ao longo do tempo (Garcia \& Velasco, 2002). Assim, Daft (1999) advoga que organizações optam por estratégias de competirem e cooperarem ao mesmo, compartilhando seus recursos essenciais, a fim de aumentar as possibilidades de ganhos para todos os envolvidos. Com essa visão, vale mais a pena que duas empresas concorrentes avancem no mercado do que, por falta de 
visão estratégica, ambas pereçam como resultado da falta de componentes essenciais. Ao escolher a estratégia de coopetição, as organizações avaliam a importância dos recursos que dispõem e o poder de monopólio que os detentores de outros recursos têm sobre sua alocação e uso (Silva, 2011).

Leão (2004) lembra que a administração estratégica assume padrão contraditório ao abordar as estratégias cooperativas como forma de criação e manutenção de vantagens competitivas, especialmente porque as teorias de competição e cooperação são caracterizadas em diferentes correntes de pensamento, que por muitas vezes se apresentam antagônicas. Embora esse fato seja relevante no contexto da administração estratégica, Dagnino e Padula (2002) defendem que, dentro do enquadramento no escopo teórico, a coopetição é uma estratégia que pode explicar a rede de interdependência estratégica entre firmas através de um sistema de criação de valores de cooperação e competição, fazendo com que esses dois aspectos evoluam conceitualmente. Desse modo, a coopetição dá origem a um novo tipo de reciprocidade estratégica entre organizações que pode ser caracterizado como um sistema coopetitivo de criação de valor. Esse modelo de estratégia organizacional leva à compreensão de que os interesses de um firma podem não estar alinhados com os interesses de seu competidor, mas que eles podem ser parcialmente unidos a fim de proporcionar recursos imprescindíveis aos envolvidos e manter o ambiente competitivo (Dagnino \& Rocco, 2009).

\section{DISCUSSÕES}

Embora as pesquisas sobre SCRM estejam ainda em estágio inicial, é possível identificar na literatura da área modelos de gestão de riscos que contemplam as peculiaridades de uma operação conjunta, como os propostos por Norrman e Jansson (2004) e Li e Hong (2007). Porém, independente do modelo escolhido para gestão de riscos por um conjunto de organizações em uma cadeia de suprimentos, a adoção de estratégias de Coopetição pode vir a ser um fator adicional que contribuirá para a minimização dos riscos. Assim, se duas cadeias de suprimentos distintas, competidoras entre si, se voltassem para a cooperação em algumas de suas atividades, ambas poderiam aumentar o potencial de ganhos estratégicos, conforme preconiza a teoria de Coopetição. Além disso, e principalmente, poderiam alavancar as práticas de SCRM ao diminuir a incidência de riscos em suas operações uma vez que a colaboração entre competidores tem o potencial de maximizar a eficiência dos envolvidos. Ao debater essa possibilidade utilizando-se a categorização de riscos elaborada por Miccuci (2008) descritas no Quadro 1, torna-se possível contextualizar e compreender melhor os benefícios da Coopetição em estratégias de mitigação de riscos em cadeias de suprimentos.
Inicialmente tem-se que os riscos de inércia são aqueles relacionados a falta de competitividade e afetam a diferenciação da cadeia frente aos seus competidores. Esses riscos são encontrados especialmente em mercados dinâmicos, onde mudanças de tecnologia ou outros aspectos afetam a cadeia de suprimentos. Uma estratégia de Coopetição pode diminuir a incidência desses riscos ao dividir os custos desprendidos em investimentos de novas tecnologias e/ou novos processos e produtos para criar uma resposta rápida às mudanças no mercado. Já os riscos de capacidade estão associados a variação da demanda percebida na cadeia. Desse modo, quando os elos da cadeia não são flexíveis a essas variações, a cadeia toda pode sofrer com alterações de capacidade. O potencial da Coopetição aqui se refere aos ganhos em escala de produção e a uma maior capacidade de flexibilização (no volume e na variedade de produtos) devido as parcerias estabelecidas para criação desse know how.

Ainda segundo Miccuci (2008), os riscos financeiros estão naturalmente associados as condições econômicas de cada elo da cadeia. Essa categoria de riscos pode incidir, por exemplo, quando há incapacidade de diminuição de custos ou variações bruscas no mercado financeiro. Aqui, uma estratégia de Coopetição pode auxiliar fornecendo, através da troca de informações e conhecimentos, um leque maior de opções de fornecedores, aumentando o poder de barganha com os mesmos. Também, a Coopetição pode fazer com que as empresas não sintam tanto as variações financeiras devido ao rateio dos seus custos e despesas financeiras e operacionais. A categoria seguinte é a dos riscos de suprimentos, que se referem ao processo de obtenção, ou seja, dificuldades que façam que o processo de obtenção de suprimentos seja mais caro que o esperado ou com a qualidade comprometida. Nesse ponto faz-se importante mencionar que a falta de redundância da cadeia pode auxiliar a incidência desses riscos. Nota-se, portanto, que a Coopetição pode ser a vir uma boa resposta ao promover o compartilhamento de recursos, tornando possível a obtenção de suprimentos não de fornecedores, mas dos próprios concorrentes, que os detêm em determinado momento.

Os riscos estratégicos, por sua vez, são inerentes a falta de uma operação conjunta como a realizada através da SCM. Quando há inexistência de visão gerencial e planejamento conjuntos, cada elo da cadeia poderá visar um objetivo próprio. A cadeia de suprimentos, assim, se expõe a riscos como situações de oportunismo, falta de investimentos em ativos específicos, entre outros. Quando se utiliza a estratégia da Coopetição, porém, esses riscos são minimizados porque existe um compartilhamento entre as empresas, onde cada uma aproveita de ativos específicos das outras e, ao mesmo tempo, também cede seus ativos, ou seja, cada empresa contribui com sua competência essencial. Seguindo com a caracterização de riscos de Miccuci (2008), tem-se que os riscos de relacionamentos estão ligados a convivência entre os 
elos da cadeia. Esses riscos podem ocorrer, por exemplo, através da exagerada dependência dos parceiros, seja ela técnica, de conhecimento, social ou de mercado. Também, se propagam pela cooperação aquém do desejável entre os elos da cadeia de suprimentos. Aqui se observa como uma estratégia de Coopetição equilibrada, onde o coopetidor não compete nem colabora mais do que o necessário, pode ser benéfica para a diminuição dos riscos de relacionamento. Por exemplo, a Coca-Cola e a Pepsi compartilhavam o mesmo fornecedor de aspartame, a NutraSweet, que por sua vez, detinha a patente do produto. Vencido o prazo da patente, uma joint venture entre duas companhias químicas, a Tosoh Corporation (japonesa) e a Dutch State Mines (holandesa) formaram a Holland Sweetener para competir com a NutraSweet. Coca-Cola e Pepsi, por sua vez, se uniram para diminuir os riscos de relacionamento com a NutraSweet (não ter uma dependência exclusiva) desse fornecedor, e passaram a considerar a Holland Sweetener como opção para o fornecimento de aspartames para a produção de refrigerantes diet. Desse modo, percebe-se que, em um movimento para diminuir seus riscos, ambas tiveram que optar por essa alternativa ou, caso contrário, correriam riscos maiores em possuir apenas um fornecedor (Nalebuff \& Brandenburger, 1996).

Uma estratégia de Coopetição também poderia ser utilizada com sucesso para tratar os riscos regulatórios ou legais, que são aqueles conectados à impossibilidade de atendimento de restrições ambientais ou legais ou, ainda, pela ocorrência de litígios em um dos membros da cadeia. A Coopetição, nesse caso, tem a capacidade de criar uma representatividade maior de empresas perante aos governos (federais, estaduais e municipais) para exercer certa pressão e cobrança para aprovação de leis e decretos que possam a vir beneficiar as empresas pertencentes a determinada cadeia de suprimentos. Tratando sobre os riscos de demanda, pode-se conceituá-lo como o risco de imprecisão entre a demanda atual e quantidade solicitada. Também, nesse ponto, as organizações precisam considerar os desdobramentos do efeito chicote, onde as quantidades nos pedidos crescem quanto mais longe a empresa está do cliente na configuração da cadeia de suprimentos (Miccuci, 2008). Esse risco pode ser minimizado através de Coopetição em canais de distribuição como, por exemplo, a parceria entre os jornais Folha de São Paulo, Estadão, Agora São Paulo e Valor Econômico, que criaram a empresa São Paulo Distribuição e Logística (SPDL) para divisão dos custos na distribuição dos jornais em todo o estado de São Paulo. Essa união gerou uma economia de aproximadamente $20 \%$ nos custos relativos as entregas de jornais para todos os envolvidos (São Paulo Distribuição e Logística [SPDL], 2011). O objetivo em criarem-se parcerias com concorrentes para a gestão da demanda em cadeias de suprimentos é alcançar respostas rápidas em toda a cadeia, não podendo a gestão da demanda ser considerada como um processo isolado. Porém, para tanto faz-se necessário compreender os limites e capacidades de cada empresa nesse processo.

Já os riscos de infraestrutura de apoio são aqueles que se associam aos ativos de cada membro da cadeia, sua infraestrutura e, também, aos sistemas de informações utilizados. Quando qualquer um desses itens não é suficiente para atender a cadeia, ou mesmo quando a flutuação de demanda sobrecarrega esses recursos, os elos da cadeia se vêem com problemas para atender aos pedidos. Assim, a Coopetição promove um compartilhamento de recursos já existentes e uma maior capacidade de investimentos em novas infraestruturas. Como exemplo, pode-se citar a cooperação entre concorrentes de telecomunicações no Brasil no compartilhamento de redes, redes de fibras ópticas, utilização de antenas, e ainda, as parcerias mercadológicas no lançamento de uma "cesta de produtos", com a utilização de recursos complementares, como forma de endereçar a busca dos clientes por um provedor único de voz fixa, voz móvel, internet e televisão (Zampese \& Zilber, 2012).

Ainda segundo Miccuci (2008), os riscos ao cliente são gerados pelos medos e desejos dos consumidores, como não atingir a expectativa pelo produto, obsolescência rápida ou até mesmo perda de confiança no produto ou marca. Desse modo, através da estratégia de Coopetição, torna-se mais fácil entregar o que o cliente espera, uma vez que uma gama maior de produtos é oferecida aos clientes, aumentando a possibilidade que esses produtos atinjam as suas expectativas. Como exemplo pode-se citar a criação da B2W Companhia Global do Varejo, em 2006, formada pela união das empresas Submarino, Lojas Americanas e Shoptime, que promoveu um aumento no volume e na variedade de produtos oferecidos, e ainda, uma maior capacidade de distribuição. Essa parceria teve o intuito também de expandir as operações para os demais países da América Latina e Índia, atingindo um valor de mercado de mais de $\mathrm{R} \$ 6,5$ bilhões e a terceira posição mundial no setor. A rede comercializa mais de 60.000 itens de 4.000 fornecedores diferentes, e a fusão garantiu opções de vendas via internet, televendas, catálogos e uma rede com mais de 500 lojas nas principais cidades do Brasil (Galo, 2011).

Por fim, a última categoria de riscos se refere aos riscos de interrupções que, como o próprio nome já diz, estão relacionados a parada não programada de qualquer fluxo da cadeia de suprimentos. Uma interrupção pode ocorrer por desastres naturais, rejeição do produto, falha de abastecimento, entre outros. Desse modo, quando duas empresas coopetem, torna-se possível diminuir a incidência dessa categoria de riscos porque a sinergia entre duas ou mais empresas competidoras cria uma velocidade de resposta maior das organizações, do que se estivessem atuando isoladamente. Essas empresas, ainda, acabam 
por alcançar um desempenho que jamais conseguiriam atingir caso não estivessem operando em conjunto.

Além dos exemplos citados até aqui, são resumidos, no Quadro 2, alguns outros modelos de utilização da estratégia de Coopetição para minimização de riscos em operações integradas e colaborativas.

\begin{tabular}{|c|c|}
\hline $\begin{array}{l}\text { CATEGORIZAÇÃO DE RISCO } \\
\text { SEGUNDO MICCUCI (2008) }\end{array}$ & EXEMPLOS DE COOPETIÇÃO \\
\hline Risco de Inércia & $\begin{array}{l}\text { As empresas Eurofarma e Biolab-Sanus formaram a joint venture Incrementha, em 2005, para o } \\
\text { desenvolvimento de tecnologias, formação de um centro de pesquisa e desenvolvimento e } \\
\text { inovação tecnológica com foco em formulações, novas indicações e novas combinações de drogas } \\
\text { já conhecidas (Santos \& Pinho, 2012). Desse modo, puderam diminuir o risco de inércia } \\
\text { associados a falta de competitividade e a habilidade de diferenciação perante os concorrentes. }\end{array}$ \\
\hline Risco de Capacidade & $\begin{array}{l}\text { Daimler e Renault-Nissan assinaram um acordo de cooperação em } 2010 \text { visando o } \\
\text { compartilhamento de componentes e desenvolvimento de carros sobre plataformas comuns, além } \\
\text { da produção de motores de baixa cilindrada com injeção direta (Lara, 2012). O objetivo da } \\
\text { parceria é aumentar a capacidade de todo os parceiros através de um substancial aumento de } \\
\text { volume, levando a economias de escala e compartilhamento de custos de desenvolvimento. }\end{array}$ \\
\hline Risco Financeiro & $\begin{array}{l}\text { A unidade européia da GM (Opel) e a PSA possuem acordo de cooperação para cortar custos e } \\
\text { desenvolver um modelo compacto, para vendas em mercados emergentes (Lara, 2012). Um dos } \\
\text { principais intuitos dessa Coopetição é diminuir os riscos financeiros das duas companhias, } \\
\text { especialmente no continente europeu, uma vez que ambas sofrem forte decréscimo nas vendas } \\
\text { devido a crise que permeia a Europa. }\end{array}$ \\
\hline Risco de Suprimentos & $\begin{array}{l}\text { Renault e Nissan possuem uma parceria estabelecida desde 1999, onde compartilham plataformas } \\
\text { e grupos motopropulsores. Além disso, cooperam em tecnologias avançadas, padronização de } \\
\text { métodos de produção e ampliação da linha de produtos. Outro objetivo dessa Coopetição é a } \\
\text { busca por coesão em compras, vendas e marketing e engenharia de veículos (Peres, 2012). Desse } \\
\text { modo, as duas companhias conseguiram diminuir os riscos de suprimentos ao obter uma sinergia } \\
\text { com fornecedores em termos de saúde financeira, qualidade e quantidade de matéria-prima } \\
\text { fornecida. }\end{array}$ \\
\hline Riscos Estratégicos & $\begin{array}{l}\text { A Shell e a Cosan anunciaram, em 2011, a criação da Raízen, joint venture entre as duas empresas } \\
\text { com o objetivo de produzir } 2,2 \text { bilhões de litros de etanol por ano para atendimento do mercado } \\
\text { interno e externo, além da produção de açúcar e energia elétrica a partir de bagaço de cana (Cosan } \\
\text { e Shell anunciam nova empresa chamada Raízen, 2011). Através da associação coopetitiva, } \\
\text { aprovada integralmente pelo governo brasileiro no fim de } 2012 \text {, essas organizações tem o } \\
\text { potencial de reduzir os riscos estratégicos de seus negócios uma vez que compartilharão } \\
\text { investimentos necessários em ativos específicos, além de conhecimentos, experiências e recursos } \\
\text { humanos particulares de seu ramo de atuação. }\end{array}$ \\
\hline Risco nos Relacionamentos & $\begin{array}{l}\text { Fiat e GM mantiveram, durante muitos anos, a holding Powertrain, para produção de motores e } \\
\text { transmissões no Brasil. Essa parceria acabou em } 2005 \text { (Lara, 2012), mas trouxe diversos } \\
\text { benefícios para as empresas como a diminuição no risco de relacionamentos com fornecedores de } \\
\text { peças de motores e transmissões nacionais. }\end{array}$ \\
\hline Risco Regulatório / Legal & $\begin{array}{l}\text { Toyota e BMW têm um acordo de cooperação para compartilhamento de motores e } \\
\text { desenvolvimento de tecnologias verdes, como motores elétricos (Lara, 2012). Desse modo, as } \\
\text { companhias têm o potencial de diminuir os riscos regulatórios e legais quanto às exigências de } \\
\text { motores que poluam menos o meio ambiente. }\end{array}$ \\
\hline Risco de Demanda & $\begin{array}{l}\text { BMW e PSA tinham, desde 2002, acordo assinado para produção de motores de baixa cilindrada } \\
\text { com tecnologias como válvulas de abertura variável e injeção direta, além de desenvolvimento de } \\
\text { veículos híbridos (Lara, 2012). Essa parceria foi encerrada em 2012, mas tinha como } \\
\text { característica a redução do risco de demanda especialmente no caso dos veículos híbridos que não } \\
\text { contam com uma base sólida de cálculo de demanda. }\end{array}$ \\
\hline Risco na Infraestrutura de Apoio & $\begin{array}{l}\text { Toyota e Subaru se uniram para o desenvolvimento do projeto e fabricação do FT-86, que } \\
\text { posteriormente se tornou os carros "Toyota GT-86" e o "Subaru BRZ" (Lara, 2012). Os carros } \\
\text { são fabricados em uma mesma fábrica no Japão, tendo o potencial de diminuir, assim, os riscos de } \\
\text { infraestrutura das duas organizações especialmente ao padronizar a comunicação entre sistemas } \\
\text { de informações com fornecedores. }\end{array}$ \\
\hline Risco ao Cliente & $\begin{array}{l}\text { A GM e AVTOVAZ, fabricante russa de automóveis, produzem em conjunto o modelo Chevrolet } \\
\text { Niva, atualização do antigo modelo Lada (Lara, 2012). Através dessa Coopetição, os riscos } \\
\text { associados aos anseios do cliente, principalmente quanto a qualidade do produto, têm o potencial } \\
\text { de ser diminuído (qualidade do modelo russo no mercado europeu e marca GM no mercado } \\
\text { russo). }\end{array}$ \\
\hline
\end{tabular}




\begin{tabular}{|l|l|}
\hline Risco de Interrupções & $\begin{array}{l}\text { GM, SAIC Motor e Wuling Motors contam com uma parceria desde 2002 na China com o intuito } \\
\text { de atender a crescente demanda doméstica por veículos automotores. Essa parceria já responde } \\
\text { pela venda de } 47,5 \% \text { do mercado local de pequenas vans comerciais (GM anuncia investimentos } \\
\text { de US\$1 bilhão na China, 2012). Desse modo, essa associação coopetitiva traz a capacidade da } \\
\text { diminuição do risco de interrupções no fornecimento dessas organizações, já que os fornecedores } \\
\text { atendem às companhias com padrões de qualidade e volume definidos pela joint venture. }\end{array}$ \\
\hline
\end{tabular}

Quadro 2 - Exemplos de Coopetição segundo a categorização de riscos de Miccuci (2008) Fonte: Elaborado pelos autores.

A partir das discussões e dos exemplos sobre a possibilidade da utilização da estratégia de Coopetição para minimização dos riscos em cadeia de suprimentos, e considerando que essa estratégia pode ser incorporada aos esforços de SCRM, desprendem-se duas proposições quanto ao papel da Coopetição na redução de incidência de riscos em cadeia de suprimentos. A primeira delas se refere à utilização da estratégia e postula que:

Proposição 1: Um coopetidor pode aumentar a capacidade de antecipação a possíveis problemas que comprometam as operações em uma cadeia de suprimentos.

A Coopetição apresenta-se como uma possível resposta às crescentes mudanças no mundo dos negócios, em um novo contexto global, onde a escolha de um posicionamento adequado para a empresa permite o controle das incertezas suscetíveis ao ambiente que possam a comprometer sua organização, ou a sua cadeia de suprimentos. Para Gnyawali e Park (2009), as empresas tornam-se mais suscetíveis a cooperação com os concorrentes quando o ciclo de vida de seu produto é curto, pela complementaridade de recursos que uma indústria pode oferecer a outra ou pela sinergia e economias de escopo. Já em indústrias com convergência tecnológica, as empresas tornam-se propensas a cooperar com os concorrentes que detêm recursos e tecnologias complementares e similaridade de recursos, aumentando as economias de escalas. Além disso, o avanço e desenvolvimento da tecnologia tornam-se mais sofisticados e complexos.

Schiavone e Simoni (2011) avançam na ideia de que o ponto principal a ser debatido em Coopetição entre empresas não são as estratégias adotadas ou não por essas empresas, mas sim o foco nos mecanismos motivadores de aprendizagem e os caminhos da evolução dos concorrentes envolvidos em algum esforço cooperativo. E ainda, questões como a história de cada empresa, seus relacionamentos, sua habilidade de explorar e aprender com seus concorrentes, os resultados atingidos em cooperações anteriores acabam, por sua vez, afetando o comportamento dessas empresas concorrentes.

Proposição 2: Uma maior resiliência da cadeia de suprimentos será alcançada quando existir uma situação de Coopetição equilibrada (cooperação e competição sendo igualmente distribuídas).

A globalização dos mercados, os avanços tecnológicos e as novas necessidades dos consumidores modificaram o modo com que as empresas realizam suas operações. De acordo com Azevedo e Matos (2006), as empresas, ao enfrentarem essas mudanças, não lidam apenas com mercados bem definidos, mas passam a enfrentar novos concorrentes, atender novos clientes e a operar em um mercado que necessita de operações globais. Para enfrentar esse novo cenário, portanto, as empresas precisam tornar-se resilientes, ou seja, ter a capacidade de suportar essas alterações e continuar operando de forma eficiente e com rápidas respostas as mudanças no ambiente. Para Yadong (2007), o entendimento da Coopetição no contexto da concorrência global advém da competição e cooperação simultâneas entre dois ou mais concorrentes em mercados globais. Desse modo, as empresas buscam alcances globais onde a concorrência pode ocorrer em diversos países, assim como em produtos diferentes. Também, essas empresas buscam complementaridade, principalmente, em inputs como tecnologia, recursos humanos, insumos e negociação com governo ou em outputs, como fechamento de contratos, fechamento de pedidos, e ainda, aumento do market share.

Devido à construção através de diferentes lógicas de interação, as relações de Coopetição são complexas. Uma parte das relações de Coopetição é movida pela lógica que os indivíduos são motivados a agirem de forma racional e egocêntrica, buscando atingir seus interesses pessoais e não participar da ação coletiva. Na visão da cooperação, que compõe a outra parte nas relações de Coopetição, é importante saber lidar com as diferenças dos indivíduos para que se possa participar de uma ação coletiva para alcançar objetivos que passam a serem comuns.

A ameaça combinada dos riscos organizacionais, inerentes à cadeia, e dos riscos ambientais tem impulsionado o grau dos riscos nas diversas operações nos negócios contemporâneos. Cada vez mais as cadeias de suprimentos investem em métricas adequadas e sistemas de gestão na busca por encontrar um equilíbrio entre os participantes (inclusive com a cooperação entre os concorrentes) para obterem uma maior resiliência da cadeia para 
diminuição de prejuízos potenciais. Essa situação de cooperação e competição equilibradas, mencionada na proposição 2 , tem como objetivo a participação de todos os elos da cadeia de suprimentos de uma forma igualitária, pois uma ruptura de qualquer participante poderá ocasionar em aumento de riscos a todos na cadeia. Assim, o objetivo dessa proposição é demonstrar que a SCRM deve buscar a Coopetição equilibrada de todos os parceiros dessa cadeia a fim de alcançar melhores resultados a todos os envolvidos.

\section{CONSIDERAÇÕES FINAIS}

Os desafios que as cadeias de suprimentos enfrentam têm se tornado cada dia mais complexos, especialmente devido as mudanças trazidas pela ampliação de mercados e desenvolvimento tecnológico. Consequentemente, os riscos a que essas cadeias se expõem são mais desafiadores e frequentes, e necessitam ser gerenciados de forma metódica para que não causem interrupções nos fluxos existentes. Assim, a SCRM pode auxiliar na diminuição da incidência de riscos ao identificar as fontes de riscos, planejar ações e sugerir medidas para mitigá-los. Do mesmo modo, é possível observar que a adoção de estratégias de Coopetição entre empresas tem o potencial de diminuir a incidência de problemas operacionais, já que as organizações trazem sua experiência e trabalham juntas para dirimir problemas enfrentados anteriormente. Portanto, é factível concluir que ao adotar essa mesma estratégia nas relações de uma cadeia de suprimentos as organizações envolvidas terão o potencial de diminuir seus riscos e trabalhar de forma a antecipar os impactos indesejáveis de uma interrupção. Nesse sentido, esse trabalho sugere que a estratégia de Coopetição seja adicionada às atividades de SCRM no intuito de aumentar a probabilidade da gestão efetiva de riscos.

As empresas em uma cadeia de suprimento poderiam cooperar com seus concorrentes para poderem criar, dentre outras possibilidades, economias de escala e aumento de vendas conjuntas através do desenvolvimento de parcerias para diminuir custos em P\&D, bem como suprir a falta de recursos tecnológicos. Isso porque sabe-se que empresas concorrentes enfrentam desafios semelhantes e possuem capacidades e recursos complementares e similares. Cada vez mais o sucesso nos negócios no mundo atual exige que as empresas adotem estratégias tanto competitivas como cooperativas ao mesmo tempo. No intuito de colaborar com as discussões sobre os benefícios da adoção da Coopetição em atividades de SCRM, esse artigo apresenta duas proposições quanto ao papel da estratégia de Coopetição aplicada à SCRM. A primeira delas versa sobre a possível capacidade que um coopetidor traz a uma cadeia de antecipar riscos e proteger todos os elos dos impactos causados por interrupções de fluxos. Já a segunda proposição debate a possibilidade de uma estratégia de
Coopetição equilibrada, onde cooperação e competição estão igualmente distribuídas, trazer a uma cadeia de suprimentos um perfil resiliente no qual os problemas enfrentados são mais facilmente superados. Desse modo, a presente pesquisa esboça algumas proposições que debatem a importância das estratégias de Coopetição para a diminuição de riscos em cadeias de suprimentos e, por conseguinte, para ajudar as estratégias de SCRM em um conjunto de organizações. É certo que as proposições aqui apresentadas requerem agora uma investigação empírica, no intuito de verificar sua aplicabilidade para os pesquisadores e gestores voltados à SCRM. Porém, acredita-se que essas proposições servem como um bom ponto de partida para compreender mais a fundo a importância e relevância da implementação da Coopetição no processo de SCRM.

\section{REFERÊNCIAS}

Azevedo, J. R., \& Matos, F. R. N. (2006, novembro). Cooperação e competição simultânea em uma rede de negócios: a coopetição na Valexport. Anais do XIII SIMPEP, Bauru, SP, Brasil, 13.

Bagshaw, M., \& Bagshaw, C. (2001). Co-opetition applied to training: a case study. Industrial and Commercial Training, 33(5), 175-177.

Banks, D. L. (2005). Foundations of Risk Analysis: A Knowledge and Decision-Oriented Perspective. Journal of the American Statistical Association,100(470).

Bengtsson, M., \& Kock, S. (2000). Coopetition in business networks - to cooperate and compete simultaneously. Industrial Marketing Management, 29(5), 411-426.

Christopher, M., \& Peck, H. (2004). Building the resilient supply chain. International Journal of Logistics Management, 15(2), 01-13.

Collins, J., \& Hussey, R. (2005). Pesquisa em administração (2a ed.). Porto Alegre: Bookman.

Cosan e Shell anunciam nova empresa chamada Raízen. (2011, fevereiro 14). Veja. Recuperado em 26 dezembro, 2012, de http://veja.abril.com.br/noticia/economia/cosan-eshell-anunciam-nova-empresa-chamada-raizen

Daft, R. L. (1999). Teoria e Projetos das Organizações (6 ed.). Rio de Janeiro: LTC - Livros Técnicos e Científicos Editora S/A.

Dagnino, G. B., \& Rocco, E. (2009). Coopetition Strategy: Theory, experiments and cases. London: Routledge. 
Dagnino, G. B., \& Padula, G. (2002, May). Coopetition strategy: a new kind of interfirm dynamics for value creation. Proceedings of the Innovative Research Management Conference, Stockholm, Sweden, 2.

Donato, F. A. S., Rossi, M. A. M., \& Bezerra, E. P. G. (2007). O Impacto de um Processo de Planejamento Colaborativo Sobre a Gestão dos Riscos na Cadeia de Suprimentos. Anais do XXVII ENEGEP, Foz do Iguaçu, SP, Brasil.

Federation of European Risk Management Associations. (2003). Norma de Gestão de Riscos. Recuperado em 15 março, 2013, de http://www.ferma.eu/wpcontent/uploads/2011/11/a-risk-managementstandard-portuguese-version.pdf

Galo, B. (2011). A B2W está fazendo água? Recuperado em 17 outubro, 2012, de http://www.istoedinheiro.com.br/noticias/72833_a+ $\mathrm{b} 2 \mathrm{w}+\mathrm{esta}+$ fazendo+agua

Garcia, C. Q., \& Velasco, C. A. (2002). Co-opetition and Perfomance: evidence from European Biotechnology Industry. Proceedings of the II Annual Conference of Euram on Innovate Research in Management, Stockholm, Sweden.

Garraffo, F. (2002, May). Types of coopetition to manage emerging technologies. Proceedings of the Innovative Research Management Conference, Stockholm, Sweden, 2.

GM anuncia investimentos de US\$ 1 bilhão na China. (2012, novembro 29). Época negócios. Recuperado em 26 dezembro, 2012, de http://epocanegocios.globo.com/Informacao/Acao/n oticia/2012/11/gm-anuncia-investimento-de-us-1bilhao-na-china.html

Gnyawali, D. R., \& Park, B. J. R. (2009). Co-opetition and Technological Innovation in Small and Medium Sized Enterprises: A Multilevel Conceptual Model. Journal of Small Business Management, 47(3), 308-330.

Guimarães, C. M., \& Carvalho, J. C. (2012). Terceirização em cuidados continuados: uma abordagem de gestão de risco. Ciência \& Saúde Coletiva, 17(5), 1179-1190.

Kimura, H., \& Perera, L. C. J. (2005). Modelo de otimização da gestão de risco em empresas não financeiras. Revista Contabilidade \& Finanças da USP, 5(37), 22-38.
Lara, R. (2012, novembro). Eu vos declaro. Revista AutoEsporte, p. 24.

Leão, D. A. (2004). Coopetição: Tipologia e impacto no desempenho das empresas da indústria de cachaça de alambique do Estado de Minas Gerais, 146 p. Dissertação (Mestrado em Administração) Universidade Federal de Pernambuco.

Li, J., \& Hong, S. (2007). Towards a new model of supply chain risk management: the cross-functional process mapping approach. Electronic Customer Relationship Management, 1(1), 91-107.

Mehr, R. I., \& Hedges, B. A. (1974). Risk management: Concepts and applications. RD Irwin.

Miccuci, V.C.G.S. (2008). Um modelo pró-ativo de gestão de riscos na cadeia de suprimentos. Tese de doutorado, Pontifícia Universidade Católica do Rio de Janeiro, Rio de Janeiro, RJ, Brasil. Disponível: http://www.maxwell.lambda.ele.pucrio.br/Busca_etds.php?strSecao=resultado\&nrSeq= 13213@2

Nalebuff, B. J., \& Brandenburger, A. M. (1996). Coopetição. Rio de Janeiro: Rocco.

Norrman, A., \& Jansson, U. (2004). Ericsson's proactive supply chain risk management approach after a serious sub-supplier accident. International Journal of Physical Distribution \& Logistics Management, 34(5), 434 -456.

Peres, L. A. (2012). Aliança Renault-Nissan dá um novo passo adiante. Recuperado em 30 novembro, 2012, de http://imprensa.quaero.com.br/economiafinancas-e-negocios/alianca-renault-nissan-da-umnovo-passo-adiante

Pires, S. R. I. (2009). Gestão da cadeia de suprimentos (supply chain management): conceitos, estratégias, práticas e casos (2a ed.). São Paulo: Atlas.

Prahalad, C. K., \& Hamel, G. (2005). Competindo pelo futuro: estratégias inovadoras para obter o controle do seu setor e criar os mercados de amanhã. Rio de Janeiro: Elsevier.

Roesch, S. M. A. (1999). Projetos de estágio e de pesquisa em administração. São Paulo: Atlas.

Santos, M. C. B., \& Pinho, M. (2012). Estratégias tecnológicas em transformação: um estudo da indústria farmacêutica brasileira. Gestão $e$ Produção, 19(2), 405-418. 
Schiavone, F., \& Simoni, M. (2011). An experiencebased view of co-opetition in $\mathrm{R} \& \mathrm{D}$ networks. European Journal of Innovation Management, 14(2), 136-154.

Sheffi, Y. (2005). The resilient enterprise: overcoming vulnerability for competitive advantage. Cambridge, MA: The MIT Press.

Silva, S. A. (2011). Alianças como estratégia de coopetição no setore de Biotecnologia: um estudo de caso na Fundação Ezequiel Dias, 92 p. Dissertação (Mestrado em Administração) Faculdades Novos Horizontes.

Singhal, P., Agarwal, G., \& Mittal, M. L. (2011). Supply chain risk management: review, classification and future directions. International Journal of Business Science and Applied Management, 6(3), 15-42.

São Paulo Distribuição e Logística. (2011). A empresa. 2011. Recuperado em 17 outubro, 2012, de http://www.spdl.com.br/Empresa.aspx

Vale, G. M. (2009). Metaestratégica: Recorrendo às Teorias Evolucionárias para Análise das Estratégias de Cooperação. Anais do 3Es: Encontro de Estudos em Estratégia. Recife, 4.

Yadong, L. (2007). A coopetition perspective of global competition. Journal of World Business, 42(2), 129-144.

Zampese, R. S., \& Zilber, M. A. (2012, agosto). Estudo de Caso de Coopetição no compartilhamento de infraestrutura entre operadores de telecomunicações no Brasil. Anais do SIMPOI, São Paulo, SP, Brasil, 15 .

Zhang, J., \& Frazier, G. V. (2011). Strategic alliance via co-opetition: supply chain partnership with a competitor. Decision Support Systems, 51, 853-863.

Zineldin, M. (2004). Co-opetition: the organization of the future. Marketing Intelligence \& Planning, 22(7), 780-789.

Zsidisin, G.A., Ragatz, G. L., \& Melnyk, S. A. (2005). Managing the dark side of supply chain management: supply continuity planning. Supply Chain Management Review, 9(2), 46-52. 